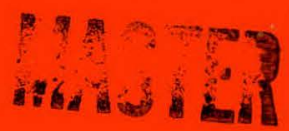

\title{
Appropriate Sizing of Solar Heating Systems
}

Paul Bendt
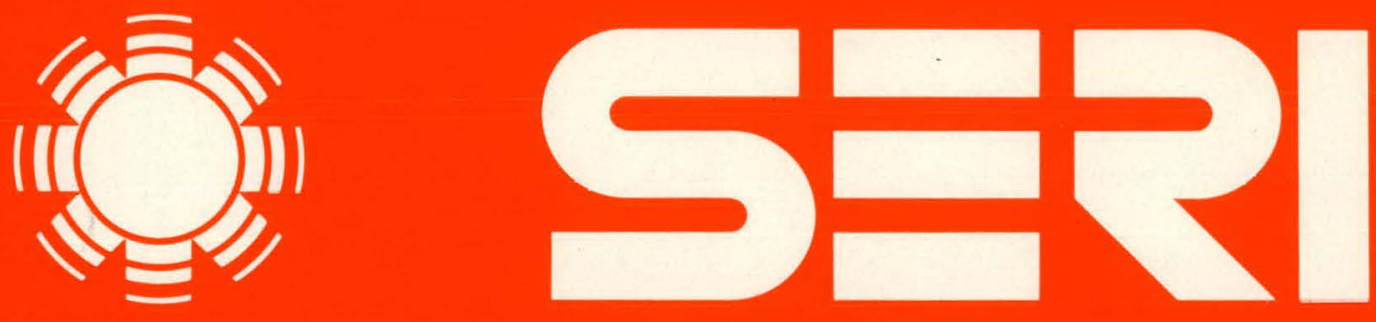

Solar Energy Research Institute

A Division of Midwest Research Institute

1617 Cole Boulevard

Golden, Colorado 80401

Operated for the

U.S. Department of Energy

under Contract No. EG-77-C-01-4042 


\section{DISCLAIMER}

This report was prepared as an account of work sponsored by an agency of the United States Government. Neither the United States Government nor any agency Thereof, nor any of their employees, makes any warranty, express or implied, or assumes any legal liability or responsibility for the accuracy, completeness, or usefulness of any information, apparatus, product, or process disclosed, or represents that its use would not infringe privately owned rights. Reference herein to any specific commercial product, process, or service by trade name, trademark, manufacturer, or otherwise does not necessarily constitute or imply its endorsement, recommendation, or favoring by the United States Government or any agency thereof. The views and opinions of authors expressed herein do not necessarily state or reflect those of the United States Government or any agency thereof. 


\section{DISCLAIMER}

Portions of this document may be illegible in electronic image products. Images are produced from the best available original document. 
Printed in the United States of America

Available from:

National Technical Information Service

U.S. Department of Commerce

5285 Port Royal Road

Springfield, VA 22161

Price:

Microfiche $\$ 3.00$

Printed Copy $\$ 4.50$

\begin{abstract}
NOTICE
This report was prepared as an account of work sponsored by the United States Government. Neither the United States nor the United States Department of Energy, nor any of their employees, nor any of their contractors, subcontractors, or their employees, makes any warranty, express or implied, or assumes any legal liability or responsibility for the accuracy, completeness or usefulness of any information, apparatus, product or process disclosed, or represents that its use would not infringe privately owned rights.
\end{abstract}


SER I /TR-333-320

UC CATEGORY: UC-59c

APPROPRIATE'SIZING. OF SOLAR HEATING SYSTEMS

PAul BendT

SEPTEMBER 1980

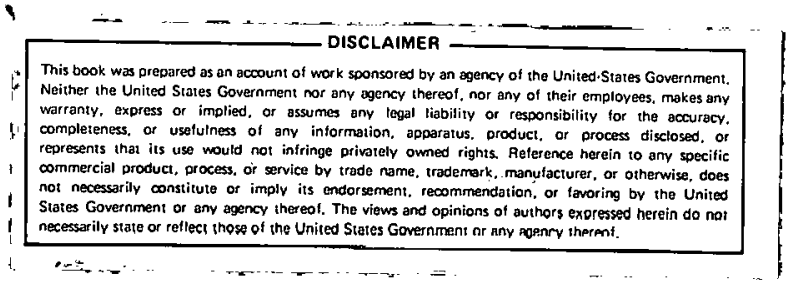

Prepared UNDER TASK NO. 3473.99

Solar Energy Research Institute

A Division of Mldwest Research Institute

1617 Cole Boulevard

Golden, Colorado 80401

Prepared for the

U.S. Department of Energy

Contract No. EG-77-C-01-4042 
THIS PAGE

\section{WAS INTENTIONALLY \\ LEFT BLANK}


$i^{x=}$

This report documents work done under task 3473.99 in the Solar Thermal Conversion Branch of the Solar Energy Research Institute.

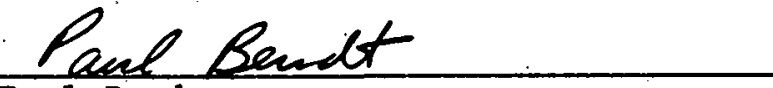

Paul Bendt

Approved for:

SOLAR ENERGY RESEARCH INSTITUTE

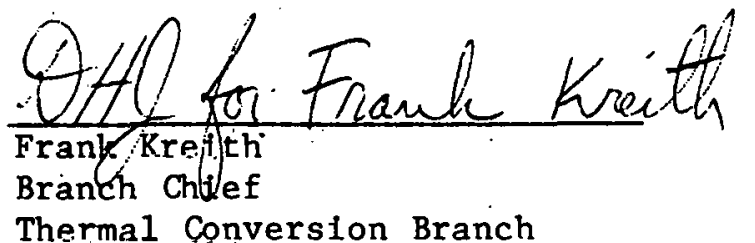

Thermal Conversion Branch

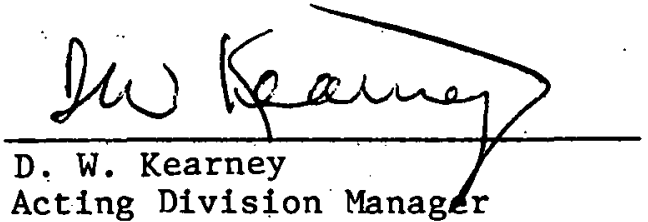

Solar Thermal, Ocean, and W1nd Division 


\section{THIS PAGE}

WAS INTENTIONALLY

LEFT BLANK . 
SEPI "in

$\mathrm{TR}-320$

SUMMARY

It is generally assumed that a solar heating system should be sized by minimiring its life cycle cost. This study shows, however, that the uncertainty in future economic trends makes the results of such a procedure questionable. The design conditions for minimum cost are extremely broad and all practical systems have a solar fraction within the limited range of $30 \%$ to 90\%. Thus, by choosing only three collector areas that give systems within this range, one is assured of selecting a nearly optimal system for any realistic economic scenario. Selecting one of these three systems is essentially equivalent to economic optimization, but simpler. Procedures are derived in this paper for determining the sizes of the three systems. The conclusion is that the collector areas should be about $1 / 8,1 / 5$, and $1 / 3$ of the building floor area. This rule of thumb eliminates the need to design solar systems individually, allowing the possibility of mass-produced homes with standardized solar heating systems.

$\mathrm{v}$ 


\section{THIS PAGE \\ WAS INTENTIONALLY \\ LEFT BLANK}


TABLE OF CONTENTS

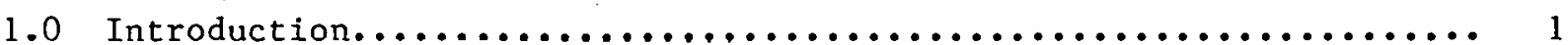

2.0 Economic Optimization of a Solar Heating System............... 3

3.0 Reasonable Economic Scenarios............................

4.0 Permissible Variation About Optimum Design................... 9

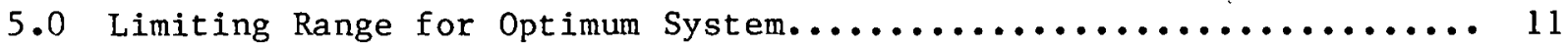

5.1 Minimum........................................ 11

5.2 Maximum....................................... 11

5.3 Acceptable Range.................................. 11

6.0 Smal1/Large Sizing Procedure............................13

7.0 Extension to other $\mathrm{Climates. \ldots \ldots \ldots \ldots \ldots \ldots \ldots \ldots \ldots \ldots \ldots \ldots \ldots \ldots \ldots \ldots \ldots \ldots \ldots \ldots}$

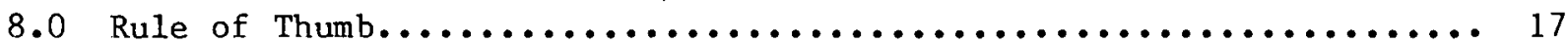

9.0 Validation........................................... 19

10.0 References.......................................... 23

Nomenclature............................................ 25 


\section{THIS PAGE}

\section{WAS INTENTIONALLY \\ LEFT BLANK}




\section{LIST OF FIGURES}

Page

2-1 Solar Fraction vs. Size for System Described in Table 2-1........ 5

9-1 Histogram of Validation Results......................... 22

\section{LIST. OF TABLES}

Page

2-1 Specifications for Sample Solar Heating System................ 4

2-2 Optimum Solar System Sizes and Benefits for Various Economic Futures............................................ 5

3-1 Specifications of Possible Economic Scenarios................. 7

4-1 Range of Nearly Optimal System Sizes........................ 9

7-1 Acceptable System Size Ranges in Different Climates.............. 15

8-1 Recommended Collector Areas............................ 17

9-1 Breakdown of Validation Results by Parameter.................. 20 
SECTION 1.0

\section{INTRODUCTION}

Choosing the collector size of a solar heating system is a more important problem than sizing a conventional heating system. For a conventional system, the primary cost is that of fuel, and the amount of fuel required to meet a given load does not depend on the furnace size. As long as the furnace is large enough to supply the load, its size is unimportant. The standard procedure is to insta 1,1 an oversized system that, much of the time, will be off, burning no fuel and costing nothing.

In contrast, for a solar system the primary cost is the initial capital investment (or the mortgage payment thereon) and this must be paid whether the system is on or off. Hence, it is economically advantageous to have a system that is operating most of the time. Accurate knowledge of the load and the performance of the collectors is therefore necessary. It is then possible to design a system that will supply the desired amount of heat without being excessively large or expensive. The present report addresses this problem of system sizing.

It is generally not practical to build a solar heating system that supplies $100 \%$ of the desired heat. A system large enough to handle the most severe weather would not be used at full capacity most of the time. It is cheaper to build a smaller solar system supplemented with a conventionally fueled furnace. A balance must then be found between the incremental expense of a larger solar system and the expense of fuel. This is an economics optimization problem.

The term "optimum" is frequently used and misused. Technically, the "optimum system" is defined as the one design, incorporating both solar and conventional heaters, that supplies the required heat for minimal total cost. It is often assumed or implied that building any other system amounts to wasting money. If, however, the additional cost of a nonoptimal system is small, an individual may choose to pay that difference for other benefits, such as architectural aesthetics, comfort, or security of energy supply. As shuwil in this report, there is substantial freedom in system design with very small added costs and thus these benefits become an important consideration. Although the "optimum system" is well defined mathematically it is not the only system worth building. It should serve only as a guide to indicate whether or not a particular design is reasonable or completely unreasonable.

The sizing problem is further complicated by economic uncertainties such as future fuel costs or collector maintenance costs. By making different assumptions about these costs, the deduced optimum systems differ tremendously, and thus economic optimization can be little more than an academic exercise.

Despite such uncertainties, architects designing solar heating systems need to be able to select appropriate sizes. This paper presents a rational approach to the task, using economic analysis but also recognizing its problems and its inability to include all considerations. The approach leads to a simple rule of thumb, and after this rule is derived it can be applied without concern for 
economics, optimization, or their attendant problems. This paper presents the derivation of the rule. II addition, a nontechnical booklet has been prepared at the Solar Energy Research Institute (Bendt and Soto 1980) to enable anyone to effectively use the rule without necessarily understanding the technical derivation.

The discussion starts by considering classical economic optimization as applied to solar heating systems. An example is used to illustrate the new approach and to derive representative values for important quantities. The next three topics are quantitative calculations of the impact of economic uncertainties, the extra cost of building a nonoptimal system, and the limits of expected variations. With these three considerations, one can then derive a sizing procedure for the sample problem that is simpler than the classical economic optimization. The next two sections generalize the prosedure so that. it covers different systems and climates, and the procedure is finally expressed as a rule of thumb. The report finally shows that the proposed rule of thumb is a satisfactory sizing procedure for a very wide range of conditions. 
SECTION 2.0

ECONOMIC OPTIMIZATION OF A SOLAR HEATING SYSTEM

The next five sections of this paper treat a particular installation and derived values that refer to it specifically. The text, however, is generally applicable to all systems, and at the end of the paper the values are generalized to apply to any building, location, collector type, and collector orientation.

Suppose one wishes to size"a solar heating system for the collectors and the home described in Table 2-1. As discussed by Beckman, Klein, and Duffie (1977), some components such as the storage tank, collector heat exchanger, and pumps should be sized proportional to collector area. Thus, by sizing the collector, one is implicitly sizing these components as well. Beckman et al. finds that other components, such as the load heat exchanger, should be sized proportional to the house heat loss. Since they give rules of thumb for sizing these other components, this issue is not addressed here. The size of the collector and the components proportional to it is addressed; thus, the one quantity, collector area (A in $\mathrm{m}^{2}$ ), completely śpecifies system size.

The f-chart method (Beckman et al. 1977), was used to analyze the performance of a solar home described in Table 2-1, and the results are plotted as the points in Fig. 2-1. These points were then fit to the functional form $f=a \ln (1+A / b)$ using nonlinear least squares to find $a$ and $b$. The resulting equation

$$
f=0.372 \ln (1+A / 6.83)
$$

is also plotted in Fig. 2-1 and gives a good fit to the data points.

The present value of the cash stream for installing, operating, and maintaining the heating system is approximately proportional to the initial cost; thus

$$
\left\langle C_{S}\right\rangle=P_{S}(2000+200 A),
$$

where $\left\langle>\right.$ denotes present value and $P_{s}$ is the proportionality constant obtained from economic analysis. Similarly, the present value of fuel costs is -

$$
\left\langle C_{f}\right\rangle=P_{f}[600(1-f)] \text {. }
$$

The total life cycle cost (LCC) is

$$
\langle C\rangle=\left\langle C_{s}\right\rangle+\left\langle C_{f}\right\rangle=P_{S}(2000+200 A)+600 P_{f}[1-0.372 \ln (1+A / 6.83)] \text {. }
$$

The minimum occurs where the derivative with respect to $A$ vanishes:

$$
0=\left.\frac{\mathrm{d}\langle\mathrm{C}\rangle}{\mathrm{dA}}\right|_{\mathrm{A}^{*}}=200 \mathrm{P}_{\mathrm{S}}+600 \mathrm{P}_{\mathrm{f}} \frac{-0.372}{\mathrm{~A}^{*}+6.83}
$$

or 


$$
A^{*}=1.12 \mathrm{P}-6.8,
$$

where

$$
P=P_{f} / P_{S}
$$

and the solar fraction at this optimum, $\mathrm{f}^{*}$, is given by

$$
\mathrm{f}^{*}=0.372 \ln (0.164 \mathrm{P}) \quad \text {. }
$$

\begin{tabular}{|c|c|}
\hline Location & Boulder, Colorado \\
\hline \multicolumn{2}{|l|}{ Collectors } \\
\hline Type & Single glazed, selective absorber, water \\
\hline$F_{r} \tau \alpha$ & 0.8 \\
\hline $\begin{array}{l}\mathrm{F}_{\mathrm{r}}^{\mathrm{r}} \mathrm{U}_{\mathrm{L}} \\
\text { Size }\end{array}$ & $\begin{array}{l}7 \mathrm{~W} / \mathrm{C} \mathrm{m}^{2} \\
1 \mathrm{~m}^{2} \text { each }\end{array}$ \\
\hline Cost & $\$ 200$ each \\
\hline Storage size & $75 \mathrm{~L}$ of water $/ \mathrm{m}^{2}$ of collector \\
\hline Load heat exchanger; $\varepsilon C_{\text {min }}$ & $600 \mathrm{~W} / \mathrm{C}$ \\
\hline House loss & $300 \mathrm{~W} / \mathrm{C}$ \\
\hline Domestic water heating load & $55 \mathrm{MJ} /$ day \\
\hline $\begin{array}{l}\text { Cost of pumps, heat exchangers, } \\
\text { ducting, etc. }\end{array}$ & $\$ 2,0000$ \\
\hline Total heating load & $100 \mathrm{GJ} / \mathrm{yr}$ \\
\hline Collector orientation & South \\
\hline Collector tilt & 55 degrees \\
\hline \multicolumn{2}{|l|}{ Payments } \\
\hline Down payment & $10 \%$ \\
\hline Term of mortgage & 20 yr at $10 \%$ interest \\
\hline Annual payments & $0.1041 \times$ initial cost \\
\hline Cost of conventional fuel & $\$ 6 / G J$ \\
\hline Fuel inflation rate & $12 \%$ \\
\hline General Inflation rate & $8 \%$ \\
\hline
\end{tabular}

Table 2-2 shows $A^{*}, f^{*}$, and relative cost $\frac{\langle C\rangle}{600 P_{f}}$ for different values of $P$.

Table 2-1. SPECIFICATIONS FOR SAMPLE SOLAR HEATING SYSTEM 


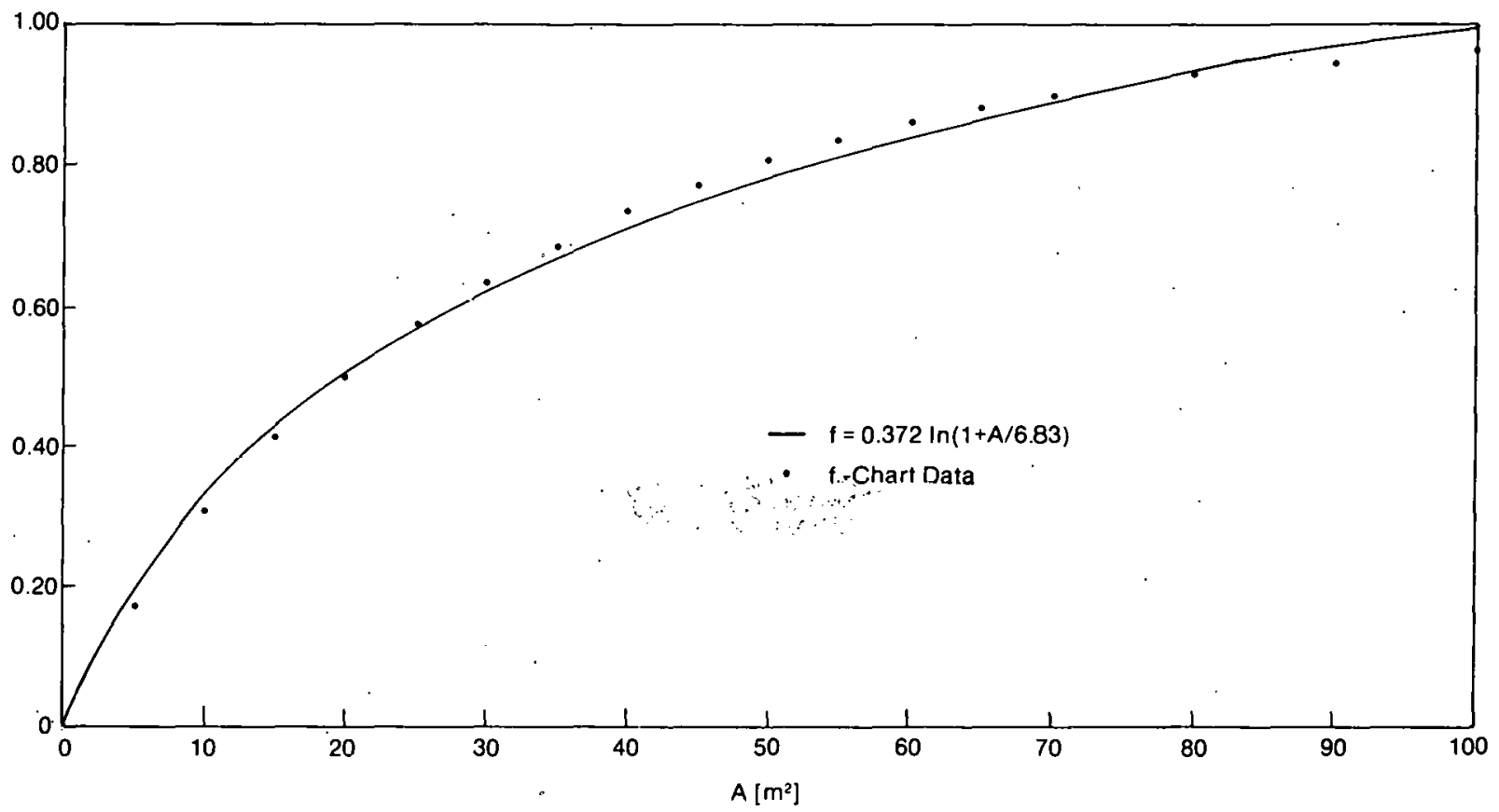

Figure 2-1. Solar Fraction vs. Size for System Described in Table 2-1

Table 2-2. OPTIMUM GOLAR SYSTEM ST7ES AND BENEFITS FOR VARIOUS ECONOMIC FUTURES

\begin{tabular}{rcccl}
\hline$P$ & $A^{*}\left(\mathrm{~m}^{2}\right)$ & $f^{*}$ & $\langle\mathrm{C}\rangle / 600 \mathrm{P}_{\mathrm{f}}$ & \multicolumn{1}{c}{ Comment } \\
\hline 5 & 0 & 0 & 1.0 & no solar system \\
7 & 1 & 0.05 & 1.47 & solar system loses $\$$ \\
10 & 4 & 0.18 & 1.29 & solar systelu loses $\$$ \\
15 & 10 & 0.33 & 1.11 & solar system loses $\$$ \\
20 & 16 & 0.44 & 0.98 & solar system savec $\$$ \\
30 & 27 & 0.59 & 0.81 & solar system saves $\$$ \\
50 & 49 & 0.78 & 0.61 & solar system saves $\$$ \\
70 & 72 & 0.91 & 0.48 & solar system saves $\$$ \\
100 & 105 & 1.00 & 0.38 & solar system saves $\$$ \\
\hline
\end{tabular}




\section{SEPI结}


Table 3-1 presents three different economic scenarios that might be used to compute the LCC of this system. The third scenario assumes a.long system life, which is achieved by periodic refurbishment of the system. As can be seen from the resulting values of $P$, the choices give very different results. For the first case, a solar system is completely impractical; for the second, it is marginal; and for the third, it is overwhelmingly beneficial. Of greater concern to the sizing problem is that the "optimum" size varies from no solar system to a $67 \mathrm{~m}^{2}, \$ 15,000+$ system, which is quite a range. But how is one to choose an economic scenario when this involves predicting the future--items like fuel costs and life expectancy? A scenario like the second is usually chosen, but there is no justification for it except that the result, marginally economic solar systems, seems intuitively correct.

Table 3-1. SPECIFICATIONS OF POSSIBLE ECONOMIC SCENARIOS

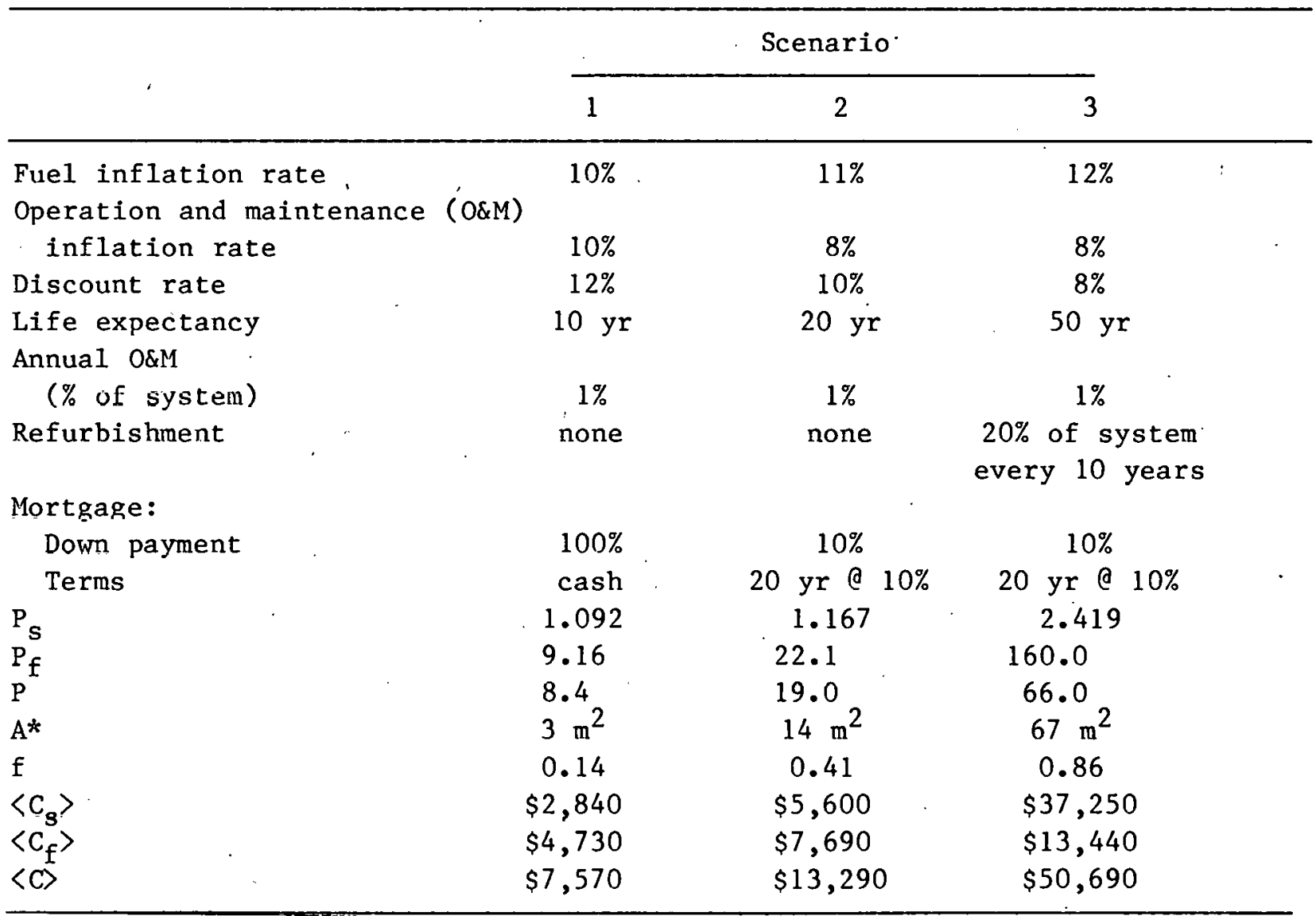


SERI 
SECTION 4.0

PERMISSIBLE VARIATION ABOUT OPTIMUM DESIGN

Once an economic scenario is chosen, the preceeding analysis can be used to obtain the size of the minimum LCC system. It is seldom possible, however, to build a system exactly this size because of architectural constraints and the fact that components are available only in standard sizes. The allowable degree of deviation from the optimal design depends on how much one is willing to lose as a result of building a system that is not optimal. Since the curve of LCC vs. size is quadratic in the vicinity of the minimum, small variations cause negligible losses. A simple criterion that is used here is that the total LCC shall not be more than $5 \%$ above the minimum possible. This is actually a very restrictive condition because the uncertainty in the total LCC can be almost an order of magnitude, as can be seen from the bottom line of Table 3-1. Using this criterion, one can calculate a range of nearly optimal system sizes, which is done in Table 4-1 for scenarios 2 and 3 . (Scenario 1 is deleted because it is unfavorable for solar energy.) As can be seen, the ranges are quite large. It is easier to express them as ranges in $f$ rather than ranges in size, and the acceptable range in $f$ is about \pm 0.15 from the optimal design.

Let $f_{\ell}^{*}$ and $f_{u}^{*}$ represent the lower and upper limits of the range of nearly optimal system sizes; then

$$
f_{\ell}^{*}=f^{*}-0.15=0.372 \ln (0.164 P)-0.15
$$

and

$$
f_{u}^{*}=f^{*}+0.15=0.372 \cdot \ln (0.164 P)+0.15
$$

The corresponding collector areas are

$$
A_{\ell}^{*}=0.75 P-6.8
$$

and

$$
\mathrm{A}_{\mathrm{u}}^{*}=1.68 \mathrm{P}-6.8 \text {. }
$$

The asterisk indicates that these values depend on the economic scenario; that 1 , they are functions of $P$. These bounds are not exactly the same as the $5 \%$ excess cost criterion, although they are close. For reasonable economic sce-

\begin{tabular}{|c|c|c|c|c|c|c|}
\hline \multirow{2}{*}{. } & \multicolumn{3}{|c|}{ Scenario 2} & \multicolumn{3}{|c|}{ Scenario 3} \\
\hline & $\min$ & opt & $\max$ & $\min$ & opt & $\max$ \\
\hline A (Size) & $5 \mathrm{~m}^{2}$ & $14 \mathrm{~m}^{2}$ & $27 \mathrm{~m}^{2}$ & $40 \mathrm{~m}^{2}$ & $64 \mathrm{~m}^{2}$ & $94 \mathrm{~m}^{2}$ \\
\hline $\mathrm{f}$ & 0.21 & 0.42 & 0.59 & 0.71 & 0.86 & 0.98 \\
\hline$\Delta \mathrm{f}$ & 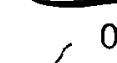 & & & & & \\
\hline
\end{tabular}
narios, in fact, these bounds are slightly more strict. Throughout this paper, the term "nearly optimal system size" refers to this range.

Table 4-1. RANGE OF NEARLY OPTIMAL SYSTEM SIZES 


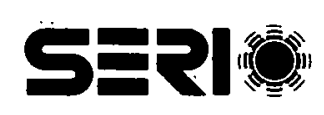


SECTION 5.0

LIMITING RANGE FOR OPTIMUM SYSTEM

\subsection{MINIMUM}

For an optimally sized solar system, the marginal cost of solar energy equals the cost of auxiliary energy. For such a system to be economical, the average cost of solar energy must be less than the cost of auxiliary energy:

$$
\begin{gathered}
\text { average cost } \\
\text { of solar energy }
\end{gathered} \quad \begin{gathered}
\text { cost of auxiliary } \\
\text { energy }
\end{gathered}=\begin{gathered}
\text { marginal cost of } \\
\text { solar energy }
\end{gathered} ;
$$

that is,

$$
\frac{\left\langle C_{s}\right\rangle}{f} \leqslant \frac{d\left\langle C_{s}\right\rangle}{d f}=\frac{d\left\langle C_{s}\right\rangle}{d A}\left(\frac{d f}{d A}\right)^{-1},
$$

or

$$
\frac{2000+200 A}{0.372 \ln (1+A / 6.83)} \leqslant 200 \frac{A+6.83}{0.372} \text {. }
$$

Solving the equality in Eq. 9 for the area gives $A=14 \mathrm{~m}^{2}$, and the inequality is satisfied for $A>14 \mathrm{~m}^{2}$. This condition corresponds to $f \geqslant 0.42$, and it is never desirable to build a system smaller than this. If a solar system is economical with $\mathrm{f}<0.42$, then building an $\mathrm{f}=0.42$ system is even more so; and if an $f=0.42$ system is not economical, then neither is any smaller system. With different costs and locations, this minimum varies from $f=0.3$ to 0.5 , but in no situation is an active system with $f \leqslant 0.3$ acceptable.

\subsection{MAXIMUM}

At the other extreme, 1 is is not practical to build a system with $f>0.9$ unless either an annual-cycle storage scheme is used or the indoor temperature is allowed to drop during long storms. The second alternative is essentially equivalent to designing an $f=0.9$ system in which auxiliary energy is simply not supplied when the solar storage cannot maintain the thermostat temperature.

\subsection{ACCEPTABLE RANGE}

When these results are combined, one can see that for a solar heating system to be economical under any reasonable economic scenario, it should deliver between 0.3 to 0.9 of the total load. This range, $0.3 \leqslant f \leqslant 0.9$, shall be called the range of "acceptable" system sizes, meaning that systems outside this range are not acceptable by any reasonable economic criteria. 
SEPI龁 


\section{SECTION 6.0 \\ SMALL/LARGE SIZING PROCEDURE}

The results from the last two sections show that: (1) an assumed economic scenario gives a nearly optimal range of \pm 0.15 about a central value, a range 0.3 wide; and (2) the acceptable range of sizes corresponds to $0.3 \leqslant \mathbf{f} \leqslant 0.9$, a range 0.6 wide. Since the width of the nearly optimal range is a significant portion of the width of the acceptable range, calculating the precise mathematical "optimum" becomes an academic excercise. For example, if a cost/performance analysis was performed for three systems with $f=0.4,0.6$, and 0.8 , one of these systems would be within \pm 0.1 of the optimum given by any scenario and thus well within the nearly optimal range. The entire process of economic analysis and optimization thus reduces to choosing one of these three sizes.

Since there are now only four distinct choices (three sizes plus the option of no solar system), it is quite easy to give the consumer a performance and cash flow analysis for each and allow him or her to choose the system that seems most appropriate. At first it may appear that this requires the consumer to make a value-based decision that was not needed in the classical economic optimization approach, but this is not so. In the classical procedure, the consumer must specify such quantities as the economic life and discount rate. The specification of economic life is a statement of how far into the future one is willing to accept the return on an investment made now; and the choice of discount rate indicates how much one is willing to pay now to receive a dollar at a future time. Such considerations involve value judgments. Most consumers are not economists and do not understand the implications of a particular choice of economic life and discount rate. However, if the consumer is offered a choice of four cash flow sequences, the options are easier to understand, the value judgments explicit, and the decision easier to make. 


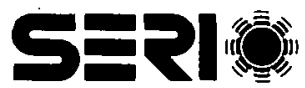


SECTION 7.0

\author{
EXTENSION TO OTHER CLIMATES
}

Thus far the discussion has focused on a particular sample installation in a particular climate. This section generalizes these results to different climates, and the next section generalizes to different installations.

In Sec. 5.0 a minimum system was derived for which the average and marginal costs of delivered energy are equal. An upper practical limit of $f=0.9$ was set, but in many climates an $f=0.9$ system cannot be justified economical1y. Another upper limit can be obtained by choosing the economic scenario that is most favorable for a solar system and still justifiable. This limit corresponds to large $P$, and a justifiable limit on $P$ is perhaps $P=50$. Thus the upper limit becomes the lesser of $f=0.9$ or $P=50$. Table $7-1$ shows the systems corresponding to these lower and upper limits in three different climates.

Table 7-1. ACCEPTABLE SYSTEM SIZE RANGES IN DIFFERENT CLIMATES

\begin{tabular}{lccc}
\hline & Albuquerque & Boulder & Seattle \\
\hline$A_{\ell}=\min$ size $\left(\mathrm{m}^{2}\right)$ & 11 & 14 & 19 \\
$\mathrm{~A}_{\mathbf{u}}=\max$ size $\left(\mathrm{m}^{2}\right)$ & 39 & 49 & 41 \\
$\mathrm{f}_{\ell}=\min$ solar fraction & 0.51 & 0.42 & 0.34 \\
$\mathrm{f}_{\mathrm{u}}=\max$ solar fraction & 0.90 & 0.78 & 0.53 \\
\hline
\end{tabular}

As can be seen, the range of the solar fraction varies substantially with climate, but the range of collector areas does not. This range of areas will be called the range of "reasonable" system sizes. The variables do not have asterisks, which indicates that they do not depend on a particular economic scenario. The total range is from 11 to $47 \mathrm{~m}^{2}$ and a complete appreciation of this range can be obtained by examining systems of 15,25 , and $40 \mathrm{~m}^{2}$; these three sizes appropriately cover the range in each location.

It may at first be puzzling that the acceptable range of system sizes is approximately the same in sunny climates like Albuquerque and cloudy climates like Seattle, but this can be easily explained. In a sunny climate, an additional square meter of collector area receives a large amount of energy. Hence, it is advantageous to increase collector size until the curve of $f$ vs. $A_{c}$ levels off at around $f=0.8$. In contrast, in a cloudy climate the marginal utility of additional collector area is small because the energy incident upon it is small. It is therefore preferable to stay in the steep region of the $f$ curve, around $f \approx 0.4$. In an intermediate climate, such as Boulder, an intermediate value, such as $f=0.6$, is expected. If an $f=0.6$ system is sized for Boulder and then built in Seattle, it will deliver less energy, about $f=0.4$, because there is less sun in Seattle. Conversely, if the same Eystcm is installed in Albuquerque, where the climate is favorable for solar 
systems, the system will perform better, around $f=0.8$. Thus the desired system size is, to first order, independent of climate.

This discussion should not be interpreted as saying that a solar system is equally practical in all locations. A system in Albuquerque will deliver more heat and save more fuel than the same system in Seattle, but the range of reasonable system sizes is similar in both climates.

Similarly, collector orientation will make a substantial difference in the amount of energy supplied by a solar heating system and an effort should be made to mount collectors at the optimum angle: due south with a tilt equal to the latitude plus twelve degrees. However, if it is not possible to optimally orient the collector, the system must still be sized. An examination of systems with orientations as far as $60^{\circ}$ from south and tilts from $15^{\circ}$ to $90^{\circ}$ shows that performance may drop by a factor of Lwu but the range of rensnnable system sizes does not change. This is not surprising in view of the climate independence discussed above. A poorly oriented collector is formally equivalent to an optimally oriented collector in a less sunny climate.

Precisely the same arguments apply to collector type. One will find that, depending on location and cost, different collector designs are most economical, but the reasonable range of system size does not change. Thus, different collector types should be compared assuming a fixed system size. 
SECTION 8.0

RULE OF THUMB

For the particular house studied, the previous section showed that the reasonable system size was between 15 and $40 \mathrm{~m}^{2}$, independent of climate, orientation, and other factors. To extrapolate to different houses, consider first the situation of two identical, neighboring houses described by Table 2-1 and each heated by solar energy. If these houses are considered together as one system, this system is described as having twice the heat loss rate, twice the collector area, and twice as much energy dellvered by solar energy. Hence the solar fraction and the economic feasibility are the same as for the single house. Thus, if the collector area is scaled proportionally to the heat loss rate, all the economic considerations remain the same. The house described in this study has a loss rate of $300 \mathrm{~W} / \mathrm{C}$, so the range of practical system sizes is about $0.05 \mathrm{~m}^{2} /\left(\mathrm{W} / \mathrm{C}\right.$ heat loss) to $0.13 \mathrm{~m}^{2} /(\mathrm{W} / \mathrm{C})$. These values scale the range of sizes so that they apply to any building size. As indicated in Sec. 6.0, it is most useful to examine three system sizes for a cost/performance comparison, so a system of intermediate size should be included. The recommended sizes are given, in metric and English units in Table 8-1.

Table 8-1. RECOMMENDED COLLECTOR AREAS

\begin{tabular}{cccc}
\hline Units & Small & Medium & Large \\
\hline $\mathrm{m}^{2}$ per W/C of building heat loss & 0.05 & 0.08 & 0.13 \\
$\mathrm{ft}^{2}$ per Btuh/F of building heat loss & 0.3 & 0.45 & 0.75 \\
\hline
\end{tabular}

Assuming a well-insulated house with a heat loss rate of about 0.4 Btuh/F per square foot of floor area, or $2.3 \mathrm{~W} / \mathrm{C} \mathrm{m}^{2}$, we can now derive a very useful rule of thumb: the collector sizes that should be considered are about $1 / 8,1 / 5$, and $1 / 3$ the floor area of the house. From here, there are many methods available to estimate performance of these systems and to predict cash flow. The consumer can then compare the options to make a decision about how large a solar heating system to install.

This rule of thumb allows designers of tract homes to plan homes with each of these system sizes and to build identical houses in different locations without designing each solar heating system individually. 
SERI絭 
SECTION 9.0

VALIDATION

In any validation, there are two critical questions. First, against what is this method to be compared? And second, what is to be the measure of comparison? Validation of this rule of thumb is complicated by the fact that it gives the purchaser the option of making choices based on intangible benefits. Therefore we must also ask: how is the choice between system sizes to be made? There are many possible procedures one can invent for validation.

Let us take a "worst case" that will test the rule of thumb most severely. First, assume the purchaser making the choice of sizes ignores all the intangibles and bases the decision only on life-cycle cost economics. Clearly, for this choice, the most severe comparison is against the LCC optimum, since by definition no method can do better when LCC is the only criterion for judgment. A simple and reliable measure of comparison is the excess cost of not having the option of selecting the "optimum" size. This excess cost is positive by definition, but a scale for judging the results is given in Sec. 4. A $5 \%$ excess cost is considered acceptable because it is small compared to the uncertainty in the LCC, which is typically a range of an order of magnitude because of uncertainties in future economics.

Having picked a procedure for validation, one must. next choose the cases to be compared. We have selected more than 32,000 cases covering a wide range of systems, houses, locations, and economics. These include not only typical cases likely to be encountered in practice, but also a large number of extreme cases for which the method is likely to break down. The cases comprise every possible combination of values of the principal quantities shown in the first column of Table 9-1. It should be noted, however, that the scaling by house size (Sec. 8) is rigorous and hence only one size of house needs to be treated in the validation. Including different heat loss rates, however, violates the assumptions of scaling and one does not expect the method to be good in such a case.

In spite of the fact that the validation procedure and cases compared are strongly biased against the rule of thumb, this method compares very favorably with the results of an optimal LCC analysis. The average excess cost is $0.725 \%$, much lower than the $5 \%$ which would have been judged acceptable. A histogram of excess cost for the 32,256 test cases is shown in Fig. 9-1. In approximately half of the cases considered the optimal solar system is none at a11; these cases are therefore grouped separately:. For these cases, the rule of thumb also will dictate no solar system and, hence, will carry no excess cost. Approximately $90 \%$ of the cases have an excess cost less than $1 \%$, and the tail extending beyond $4 \%$ excess cost (approximately $4 \%$ of the cases) represents the "wild cases" composed of combinations of extreme values of the design parameters. It is also useful to have a breakdown of the histogram for particular values of the parameters; this breakdown is given in Table 9-1.

The rule of thumb is a simple, easy-to-use method that can include intangible benefits and avoids economic uncertainties. At the same time, this validation shows that the rule of thumb is also a very good method when judged by classical economic considerations. 
Table 9-1. BREAKDOWN OF VALIDATION RESULTS BY PARAMFTER

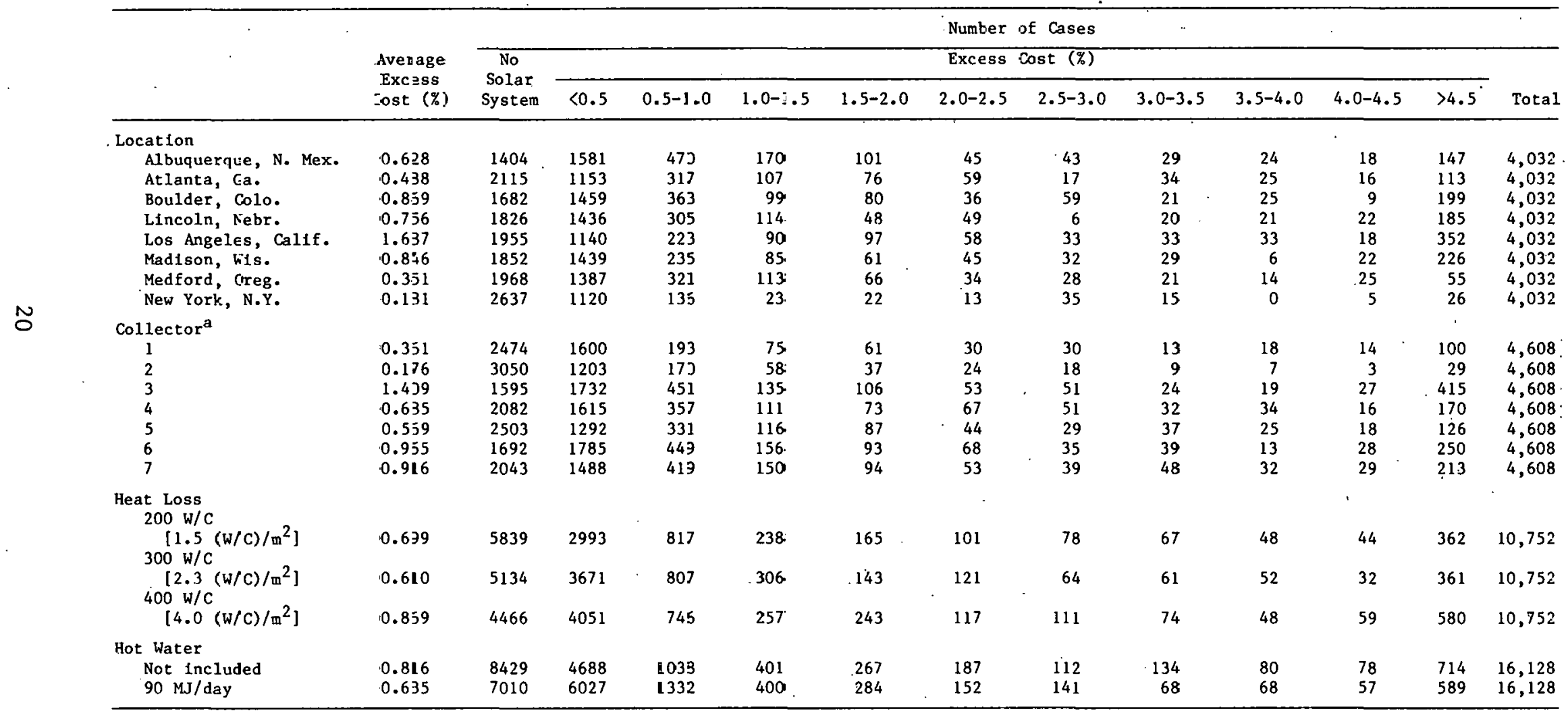


Table 9-1. BREAKDOWN OF VALIDATION RESULTS BY PARAMETER (Concluded)

\begin{tabular}{|c|c|c|c|c|c|c|c|c|c|c|c|c|c|}
\hline \multirow[b]{3}{*}{. } & \multirow{3}{*}{$\begin{array}{l}\text { Average } \\
\text { Excess } \\
\text { Cost }(\%)\end{array}$} & \multirow{3}{*}{$\begin{array}{c}\text { No } \\
\text { Solar } \\
\text { System }\end{array}$} & \multirow{2}{*}{\multicolumn{10}{|c|}{$\begin{array}{l}\text { Number of Cases } \\
\text { Excess Cost }(\%)\end{array}$}} & \multirow[b]{3}{*}{ Total } \\
\hline & & & & & & & & & & & & & \\
\hline & & & $<0.5$ & $0.5-1.0$ & $1.0-1.5$ & $1.5-2.0$ & $2.0-2.5$ & $2.5-3.0$ & $3.0-3.5$ & $3.5-4.0$ & $4.0-4.5$ & $>4.5$ & \\
\hline \multicolumn{14}{|l|}{ Fuel Cost } \\
\hline$\$ 4 / G J$ & 0.272 & 6031 & 1280 & 304 & 98 & 87 & 50 & 25 & 33 & 27 & 18 & 111 & 8,064 \\
\hline$\$ 6 / G J$ & 0.525 & 4154 & 2569 & 622 & 177 & 122 & 65 & 42 & 45 & 32 & 26 & 210 & 8,064 \\
\hline$\$ 8 / G J$ & 0.836 & 2983 & 3272 & 702 & 27.2 & 147 & 106 & 86. & 45 & 45 & 51 & 355 . & $8,064^{\circ}$ \\
\hline$\$ 10 / \mathrm{GJ}$ & 1.271 & 2271 & 3594 & 742 & 254 & 195 & 118 & 100 & 79 & 44 & 40 & 627 & 8,064 \\
\hline \multicolumn{14}{|l|}{ Solar Fixed Costs } \\
\hline$\$ 1000$ & 1.249 & 2762 & 2995 & 728 & 329 & 24 & 148 & 100 & 103 & 69 & 67 & 552 & 8,064 \\
\hline$\$ 2000$ & 0.722 & 3628 & 2852 & 629 & 211 & 153 & 87 & 72 & 48 & 34 & 29 & 321 & 8,064 \\
\hline$\$ 3000$ & 0.513 & 4274 & 2576 & 549 & 144 & 109 & 59 & 45 & 26 & 28 & 20 & 234 & 8,064 \\
\hline$\$ 4000$ & 0.418 & 4775 & 2292 & 464 & 117 & 78 & 45 & 36 & 25 & 17 & 19 & 196 & 8,064 \\
\hline \multicolumn{14}{|l|}{ Ezonom1c Scenario } \\
\hline$P=10$ & 0.007 & 5347 & 15 & 3 & 3 & 2 & 1 & 1 & 1 & 1 & 0 & 2 & 5,376 \\
\hline$P=20$ & 0.237 & 4260 & $67 j$ & 154 & 54 & 56 & 36 & 18 & 20 & 20 & 12 & 69 & 5,376 \\
\hline$P=30$ & 0.512 & 2717 & 1757 & 406 & 117 & 90 & 50 & 29 & 33 & 27 & 18 & 132 & 5,376 \\
\hline$P=40$ & 0.794 & 1626 & 2477 & 532 & 197 & 116 & 77 & 53 & 35 & 33 & 25 & 205 & 5,376 \\
\hline$P=50$ & 1.154 & 951 & 2874 & 597 & 185 & 142 & 84 & $\therefore \quad 73$ & 61 & 32 & 25 & 352 & 5,376 \\
\hline$P=60$ & 1.652 . & 538 & 2915 & 678 & 245 & 145 & 91 & .79 & 52 & 35 & 55 & 543 & 5,376 \\
\hline TOTAL & 0.725 & 15,439 & $10,715^{\circ}$ & 2370 & 801 & 551 & 239 & 253 & 202 & 148 & 135. & 1303 & 32,256 \\
\hline
\end{tabular}

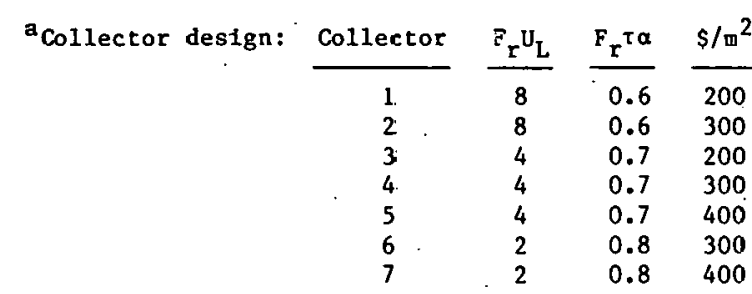




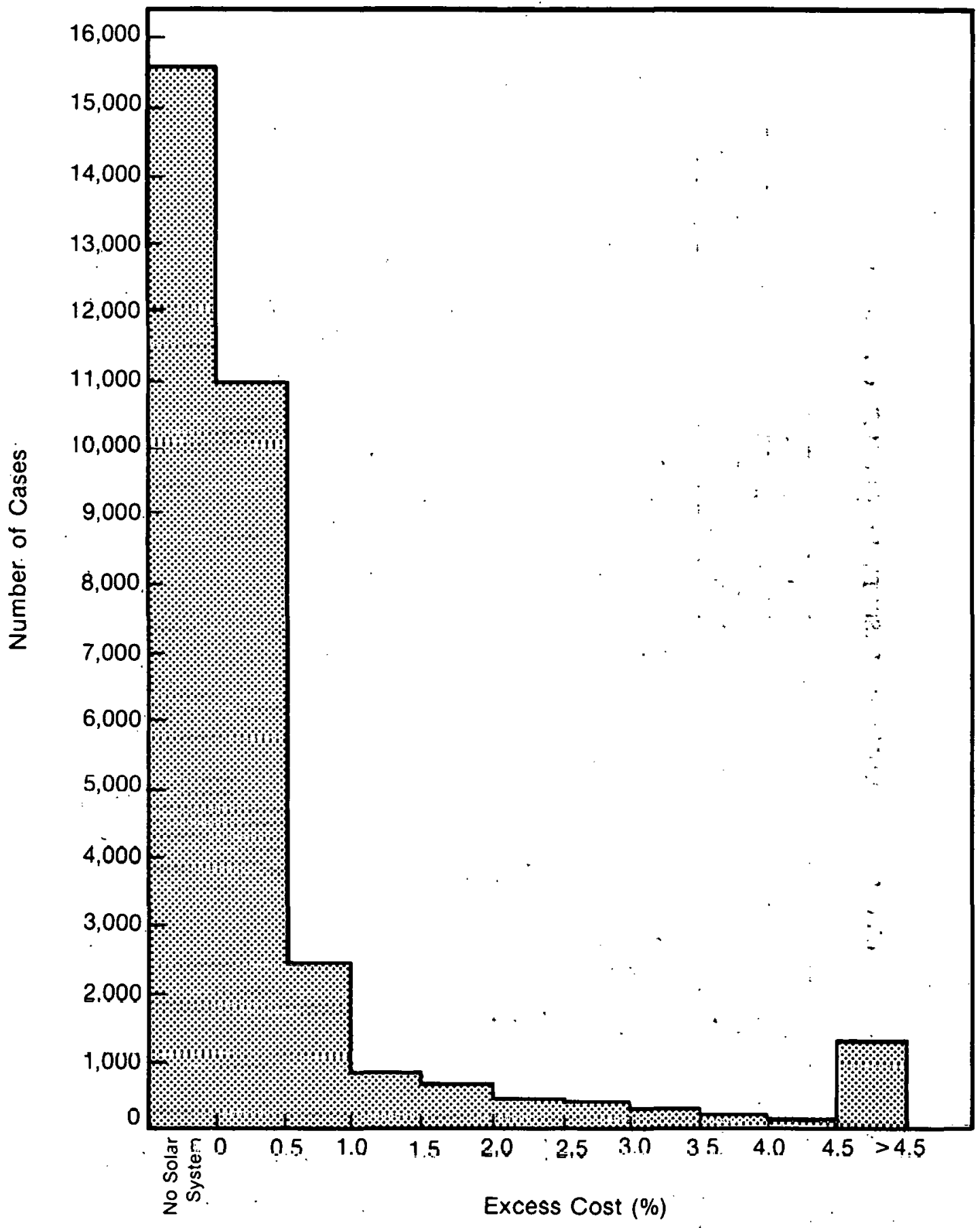

Figure 9-1. Histogram of Validation Results 


\section{SECTION 10.0}

\section{REFERENCES}

Beckman, W.; Klein, S.; Duffie, J. 1977. Solar Heating Design by the f-Chart Method. New York: John Wiley \& Sons.

Bendt, P.; Soto, R. 1980. Homeowner's Solar Sizing Workbook: A Simplified Method for Sizing Active Solar Space Heating Systems. SP-722-342. Golden, CO: Solar Energy Research Institute. 
$\stackrel{i=-\infty}{i=-1}$

NOMENCLATURE

A collector area in $\mathrm{m}^{2}$, representing system size

$A^{*} \quad$ optimal collector area for a given economic scenario

$A_{\ell}^{*}, A_{u}^{*} \quad$ lower and upper limits of the nearly optimal range of collector areas for a given economic scenario

$\mathrm{A}_{\ell}, \mathrm{A}_{\mathrm{u}} \quad$ lower and upper limits on the reasonable range of collector areas; independent of economics

$\langle C\rangle$ present value of total energy costs

$\left\langle\mathrm{C}_{\mathrm{f}}\right\rangle \quad$ present value of auxiliary energy costs

$\left\langle C_{s}\right\rangle$ present value of solar system costs

f

solar fraction corresponding to a particular system size

$f *$

$\mathrm{f}_{\ell}^{*}$

$\mathrm{f*}$

$\mathrm{f}_{\ell}$

$\mathrm{f}_{\mathrm{u}}$

$F_{r} \tau \alpha$

solar fraction corresponding to $A^{*}$

solar fraction corresponding to $A_{\ell}^{*}$

solar fraction corresponding to $A_{u}^{*}$

solar fraction corresponding to $A_{\ell}$

solar fraction corresponding to $A_{u}$

$\mathrm{F}_{\mathrm{r}_{\mathrm{L}}}$

collector optical efficiency

ln

$\mathrm{P}_{\mathbf{S}}$

$P_{f}$

$P$

collector heat loss rate

natural logarithm function, base e

cash-flow-to-present-value conversion factor for solar system

cash-flow-to-present-value conversion factor for auxiliary fuel

ratio of $\mathrm{P}_{\mathrm{f}} / \mathrm{P}_{\mathrm{S}}$, a factor representing an economic scenario 


\begin{tabular}{|c|c|c|c|}
\hline $\begin{array}{c}\text { Document Control } \\
\text { Page }\end{array}$ & $\begin{array}{r}\text { 1. SERI Report No. } \\
\text { TR-333-320 }\end{array}$ & $\begin{array}{l}\text { 2. NTIS Accession No. } \\
\text {. }\end{array}$ & 3. Recipient's Accession No. \\
\hline \multirow{2}{*}{\multicolumn{3}{|c|}{$\begin{array}{l}\text { 4. Title and Subtitle } \\
\text { Appropriate Sizing of Solar Heating Systems }\end{array}$}} & $\begin{array}{l}\text { 5. Publication Date } \\
\quad \text { September } 1980\end{array}$ \\
\hline & & & 6. \\
\hline & 8. Performing Organization Rept. No \\
\hline \multicolumn{3}{|c|}{$\begin{array}{l}\text { 9. Performing Organization Name and Address } \\
\text { Solar Energy Research Inst itute } \\
1617 \text { Cole Boulevard } \\
\text { Golden, Colorado } 80401\end{array}$} & \begin{tabular}{|l} 
10. Project/Task/Work Unit No. \\
$\frac{3473.99}{}$ \\
11. Contract (C) or Grant (G) No. \\
"(C) \\
(G)
\end{tabular} \\
\hline \multirow{2}{*}{\multicolumn{3}{|c|}{ 12. Spnnsoring Organization Name and Address }} & $\begin{array}{l}\text { 13. Type of Report \& Period Covered } \\
\text { Technical Report }\end{array}$ \\
\hline & & & 14. \\
\hline
\end{tabular}

15. Supplementary Notes

16. Abstract (Limit: 200 words)

It is generally assumed that a solar heating system should be sized by minimizing its life cycle cost. This study shows, however, that the uncertainty in future economic trends makes the results of such a procedure questionable. The design conditions for minimum cost are extremely broad and all practical systems have a solar fraction within the limited range of $30 \%$ to $90 \%$. Thus, by choosing only three collector areas that give systems within this range, one is assured of selecting a nearly optimal system for any realistic economic scenario. Selecting one of these three systems is essentially equivalent to economic optimization, but simpler. Procedures are derived in this paper for determining the sizes of the three systems. The conclusion is that the collectur dreas should bc about $1 / 8$, $1 / 5$, and $1 / 3$ of the building floor area. This rule of thumb eliminates the need to design solar systems individually, allowing the possibility of mass-produced homes with standardized solar heating systems.

17. Dnsııment Analysis

a. Descriptors Solar Heating Systems; Space Healing; jizing; Solar Cullectors; Economic. Aspects; Optimization

b. Identifiers/Open-Ended Terms

\section{c. UC Categories}

$59 \mathrm{c}$

18. Availability Statement

National Technical Information Service

U.S. Department of Commerce

5285 Port Royal Road

Springfield, Virginia 22161

19. No. of Pages

31

20. Price

$\$ 4.50$ 